\title{
THE SIGNIFICANCE OF IRON AND MANGANESE IN THE PHOSPHORUS IMMOBILIZATION INTO SEDIMENTS OF THE PRUT AND DNIESTER RIVERS (REPUBLIC OF MOLDOVA)
}

\author{
Larisa Postolachi ${ }^{1}$, Vasile Rusu ${ }^{1}$, Tudor Lupascu ${ }^{1}$ \\ 1 Institute of Chemistry of Academy of Sciences of Moldova, 3 Academiei str., \\ Chisinau, \\ MD-2028, Republic of Moldova, *e-mail: larisa.postolachi@gmail.com
}

\begin{abstract}
The interdependence of phosphorus content with iron and manganese concentration in sediments of the Prut and Dniester Rivers was established. The methodology of sampling in accordance with recommendations of the American Geological Agency was used. The Fe and $\mathrm{Mn}$ content was determined by the flame atomic absorption spectroscopy. In order to establish the phosphorus content in water, bottom sediments and its interstitial water the methodology and procedures recommended by World Health Organization were applied.

The recorded ratio of total iron and phosphorus at sediments surface along the Prut and Dniester Rivers was, in the most cases, greater than 15. This fact indicates that in sediments there is enough iron to control the flux of phosphorus from sediments in the water horizon. In interstitial water the $\mathrm{Fe}_{\text {diss: }}$ :-P ratio was greater than 3.6, suggesting that the sediments have a high affinity to phosphates, immobilized its.

In bottom sediments of the Prut and Dniester Rivers the manganese and iron content has correlated positively with the phosphorus forms amount.
\end{abstract}

Keywords: bottom sediments, interstitial water, iron, manganese, phosphorus.

\section{Introduction}

Phosphorus fate in soils and sediments is influenced by the redox potential. Under oxidizing conditions, hydroxides of iron and manganese have a substantial role in the phosphorus adsorption [1]. The concentration of phosphorus bound with iron has depended on the sediment type and its humidity, the content of organic matter. Therewith, the phosphorus content in sediments is directly connected with the amount of total dissolved iron in the interstitial water [2].

In the specialty literature there are present the results revealing the significance of $\mathrm{Fe}$ and $\mathrm{Mn}$ in the formation of metal-P complexes and the immobilization of phosphorus [2-7].

Both phosphorus and iron play a very important role in the aquatic medium, because these elements are essential as electron acceptors in oxidation/reduction processes taking place during organic matter degradation in sediments and in water layer above bottom sediments. Iron plays an essential role in photosynthesis and it has been suggested to be a potential factor limiting phytoplankton production. Phosphate concentrations are greatly affected by processes taking place in sediments; therefore, there is an obvious need for better understanding of phosphorus transformations in sediments [2].

During organic matter degradation, phosphorus is mobilized in interstitial water of sediments. Also, phosphorus can be mobilized in interstitial water through desorption 
and reduction of $\mathrm{Fe}^{3+}$ ions. The classic model describing the P-release from sediments to water links the release to the iron cycle. In anoxic conditions, insoluble $\mathrm{Fe}^{3+}$ ions are reduced to dissolved $\mathrm{Fe}^{2+}$ ions and $\mathrm{Fe}$-bound $\mathrm{P}$ is released into interstitial water. When dissolved $\mathrm{Fe}^{2+}$ formed in dissimilatory $\mathrm{Fe}^{3+}$ reduction is diffused towards oxic sediment surface or further to near-bottom water, it is re-oxidized to $\mathrm{Fe}^{3+}$. The precipitated $\mathrm{Fe}^{3+}$ oxides are considered to bind $P$ and thus effectively prevent the concomitant diffusion of $P$ to overlying water. Sediments of water bodies with high oxygen amount are often characterized by a high content of iron oxides [4].

The predominant Fe:P surface complexation ratio of $\mathrm{Fe}(\mathrm{OOH})$ is suggested to be 2 mol:mol, which corresponds mass ratio of $3.6 \mathrm{w}: \mathrm{w}$. The low Fe:P ratio $(<3.6)$ indicated high efflux of phosphorus, suggesting that there was not enough diffusing Fe to form $\mathrm{Fe}^{3+}$ in the oxic surface zone of the sediments or near-bottom water to bind the $\mathrm{P}$ diffusing from the sediments. Thus, phosphorus is released into water column [4].

Jensen and coworkers concluded that the Fe:P molar ratio has a direct impact on the magnitude of phosphorus release. Presented results indicate that the Fe:P ratio above 15 (by weight) may be possible to control internal P-loading by keeping the surface sediment oxidized [5].

The aim of presented work was to establish the interdependence of phosphorus amount with iron and manganese content in sediments of the Prut and Dniester Rivers.

\section{Experimental}

Sampling. The methodology of sampling in accordance with recommendations of the American Geological Agency (AGA) was used [8]. Samples were collected using allplastic dredge sampler, fresh material being wet-sieved through 2-mm all-plastic sieve. During the transportation, the samples were stored in the portable refrigerator at $4^{\circ} \mathrm{C}$. Analytical procedures. In the laboratory the water samples were filtered through the membrane filter $(0.45 \mu \mathrm{m})$ and preserved with $\mathrm{HNO}_{3}$, in accordance with recommendations of the World Health Organization [WHO, 9]. In order to identify the total content of heavy metals in freshly sampled sediments there was used the extraction procedure recommended by AGA [8]. For interstitial water extraction there was used the centrifugation of fresh (wet) sediments. Then, the supernatant was filtered through membrane filter $(0.45 \mathrm{~mm})$ and stored in the dark at $4^{\circ} \mathrm{C}$ until analysis. The Fe and $\mathrm{Mn}$ content was determined using the flame atomic absorption spectroscopy.

In order to establish the phosphorus content in water and interstitial water the methodology and procedures recommended by WHO were used [9]. In sediment there were determined (i) inorganic phosphorus, (ii) organic phosphorus and (iii) the total content of phosphorus. For analysis the fresh sediment samples were used. The total phosphorus content was determined according to recommendations of AGA [8]. The content of inorganic phosphorus was determined in accordance with WHO recommendations for inorganic suspended phosphorus [9]. The content of organic phosphorus was determined by the subtraction of inorganic phosphorus content from the total content. The phosphorus content in interstitial water of the sediments was determined after centrifugation of fresh (wet) sediments [10].

\section{Results and discussion}

Along the Prut River the ratio of total iron and phosphorus (Fetot: $\left.P_{t o t}\right)$ at sediments surface $(0-5 \mathrm{~cm})$ have ranged within 16-30 (Tab. 1), and along the Dniester Riverwithin 6-31 (Tab. 2). The low values $(<8)$ of Fetot: $P_{\text {tot }}$ ratio supposed the reduced 
capacity adsorption of sediments towards phosphates or even a saturation of sorption sites, followed by a mobilization of phosphates in water layer above sediments [11].

Table 1. Ratio of iron and phosphorus $\left(\mathrm{Fe}_{\text {tot }}\right.$ : $\left.\mathrm{P}_{\text {tot }}\right)$ in the bottom sediments (BS). Ratio of dissolved iron and phosphorus-orthophosphate $\left(\mathrm{Fe}_{\text {diss }}: \mathrm{O}-\mathrm{P}\right)$ in interstitial water (IW) along the Prut River.

\begin{tabular}{|c|c|c|c|c|c|c|c|c|}
\hline \multirow[b]{3}{*}{ Molar ratio } & \multicolumn{8}{|c|}{2009} \\
\hline & \multicolumn{4}{|c|}{ Spring } & \multicolumn{4}{|c|}{ Summer } \\
\hline & 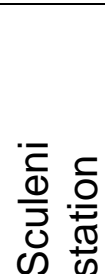 & 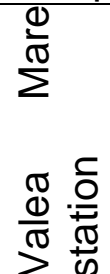 & 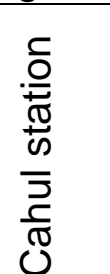 &  & 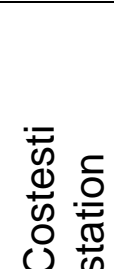 & 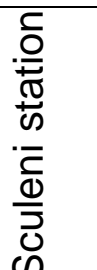 & 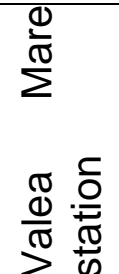 &  \\
\hline $\mathrm{Fe}_{\text {tot }}: \mathrm{P}_{\text {tot }}(\mathrm{BS})$ & 30 & 17 & 26 & 30 & 21 & 17 & 25 & 20 \\
\hline Fediss: o-P (IW) & 6.9 & 24 & 6.1 & 7.7 & 5 & 13 & 5.2 & 2.8 \\
\hline \multirow{5}{*}{$\begin{array}{l}F e_{\text {tot: }}: P_{\text {tot }}(\mathrm{BS}) \\
F e_{\text {diss }}: 0-P(I W)\end{array}$} & \multicolumn{8}{|c|}{2010} \\
\hline & & $\begin{array}{l}\text { leni } \\
\text { ion }\end{array}$ & $\begin{array}{r}\text { Vale } \\
\text { st }\end{array}$ & $\begin{array}{l}\text { Mare } \\
\text { ion }\end{array}$ & & $\begin{array}{l}\text { ahul } \\
\text { tion }\end{array}$ & & $\begin{array}{l}\text { lita Prut } \\
\text { tation }\end{array}$ \\
\hline & \multicolumn{8}{|c|}{ Spring } \\
\hline & \multirow{2}{*}{\multicolumn{2}{|c|}{7.3}} & \multirow{2}{*}{\multicolumn{2}{|c|}{$\frac{10}{92}$}} & \multirow{2}{*}{\multicolumn{2}{|c|}{$\frac{1}{2}$}} & \multicolumn{2}{|r|}{18} \\
\hline & & & & & & & & 5.6 \\
\hline
\end{tabular}

Such values were recorded only episodically for the Dniester River sediments (station Oxentia, 2009). In most cases, the molar ratio Fetot: $P_{\text {tot }}$ is greater than 15 . This fact indicates that in sediments there is enough iron to control the flux of phosphorus from sediments into water horizon [4].

In interstitial water the dissolved iron and phosphorus-orthophosphate (Fediss:o-P) greater than 3.6 indicates a high capacity of sediments to phosphorus immobilization in oxic conditions. Conversely, a low ratio Fe:o-P $(<3.6)$ indicates a high release of orthophosphates from sediment into water horizon without corresponding high iron amount [4].

The Fediss: $0-P$ ratio in interstitial water of the Prut River sediments was ranged from 2.3 to 24 (Tab. 1) and in pore water of the Dniester River sediments - from 1.4 to 11 (Tab. 2). In most cases, the molar ratio Fediss:o-P was greater than 3.6. This fact suggests that the sediments have a high affinity to phosphates, immobilized its.

In specialty literature there are presented data for various water bodies, where in bottom sediments the content of iron and manganese correlated positively with the phosphorus amount in sediments $[4,5,12]$. During of spring, in bottom sediments of the Prut River the manganese and iron content has correlated positively with the phosphorus forms: $M_{\text {tot }}-P_{\text {tot }}(r=0.79), M_{\text {tot }}-P_{\text {inorg }}(r=0.75)$, Fetot $-P_{\text {tot }}(r=0.99)$, also, during of summer: $M_{\text {tot }}-P_{\text {tot }}(r=0.97), M_{\text {tot }}-P_{\text {inorg }}(r=0.98), M_{\text {tot }}-P_{\text {org }}(r=0.99)$, Fetot $P_{\text {tot }}$ $(r=0.89)$, Fetot $-P_{\text {org }}(r=0.99)($ Tab. 3). 
Table 2. Ratio of iron and phosphorus $\left(\mathrm{Fe}_{\text {tot }}\right.$ : $\left.\mathrm{P}_{\text {tot }}\right)$ in the bottom sediments (BS). Ratio of dissolved iron and phosphorus-orthophosphate ( $\left.\mathrm{Fe}_{\text {diss: }}: \mathrm{O}-\mathrm{P}\right)$ in interstitial water (IW) along the Dniester River.

\begin{tabular}{|c|c|c|c|c|c|}
\hline \multirow{3}{*}{ Molar ratio } & \multicolumn{5}{|c|}{2009} \\
\hline & $\begin{array}{l}\text { Oxenti } \\
\text { a } \\
\text { station }\end{array}$ & $\begin{array}{c}\text { Vadul lui } \\
\text { Voda station }\end{array}$ & $\begin{array}{l}\text { Oxentia } \\
\text { station }\end{array}$ & $\begin{array}{l}\text { Malovat } \\
\text { a station }\end{array}$ & $\begin{array}{l}\text { Vadul lui Voda } \\
\text { station }\end{array}$ \\
\hline & \multicolumn{2}{|c|}{ Spring } & \multicolumn{3}{|c|}{ Summer } \\
\hline$F e_{\text {tot }}: P_{\text {tot }}(B S)$ & 6 & 14 & 10 & 12 & 13 \\
\hline Fe diss: $0-P(I W)$ & - & 8.9 & 4.9 & 1.3 & 7.2 \\
\hline \multirow[b]{4}{*}{$F e_{\text {tot }}: P_{\text {tot }}(B S)$} & \multicolumn{5}{|c|}{2010} \\
\hline & \multicolumn{2}{|c|}{ Oxentia station } & \multicolumn{3}{|c|}{ Vadul lui Voda station } \\
\hline & \multicolumn{5}{|c|}{ Spring } \\
\hline & \multicolumn{2}{|r|}{20} & \multicolumn{3}{|c|}{31} \\
\hline Fediss: o-P (IW) & \multicolumn{2}{|r|}{11} & \multicolumn{3}{|c|}{0.4} \\
\hline
\end{tabular}

Table 3. Pearson correlations between the metals ( $\mathrm{Mn}, \mathrm{Fe})$ and phosphorus forms content in interstitial water and bottom sediments of the Prut and Dniester Rivers

\begin{tabular}{|c|c|c|c|c|}
\hline Prut River & Corelation & Season & $r^{* *}$ & Relationship \\
\hline \multirow{3}{*}{ Interstitial water } & $\mathrm{Fe}_{\text {diss }}{ }^{-} 0-\mathrm{P}^{\star}$ & spring & 0.8922 & $\mathrm{C}^{\mathrm{Fe}}=15 \cdot \mathrm{C}^{\mathrm{o}-\mathrm{P}}+69.79$ \\
\hline & Fediss- $0-P$ & summer & 0.8790 & $\mathrm{C}^{\mathrm{Fe}}=5.89 \cdot \mathrm{C}^{\mathrm{o}-\mathrm{P}}+148$ \\
\hline & $\mathrm{Fe}_{\text {diss }}-\mathrm{P}_{\text {cond }}$ & summer & 0.9957 & $\mathrm{C}^{\mathrm{Fe}}=12.89 \cdot \mathrm{C}^{\mathrm{Pcond}}-246$ \\
\hline \multirow{8}{*}{$\begin{array}{l}\text { Sediments } \\
(0-5 \mathrm{~cm})\end{array}$} & $\mathrm{Mn}_{\text {tot }}-\mathrm{P}_{\text {tot }}$ & spring & 0.7958 & $\mathrm{C}^{\mathrm{Mn}}=1.73 \cdot \mathrm{C}^{\text {Ptot }}-97.78$ \\
\hline & $\mathrm{Mn}_{\text {tot }}-\mathrm{P}_{\text {tot }}$ & summer & 0.9781 & $C^{\mathrm{Mn}}=0.36 \cdot \mathrm{C}^{\mathrm{Ptot}}+125$ \\
\hline & $M n_{\text {tot }}-P_{\text {inorg }}$ & spring & 0.7550 & $\mathrm{C}^{\mathrm{Mn}}=1.56 \cdot \mathrm{C}^{\text {Pinorg }}+1.1$ \\
\hline & $M n_{\text {tot }}-P_{\text {inorg }}$ & summer & 0.9830 & $\mathrm{C}^{\mathrm{Mn}}=1.96 \cdot \mathrm{C}^{\text {Pinorg }}+92.7$ \\
\hline & $M n_{\text {tot }}-P_{\text {org }}$ & summer & 0.9946 & $C^{M n}=9.65 \cdot C^{\text {Porg }-487}$ \\
\hline & Fetot- $P_{\text {tot }}$ & spring & 0.9998 & $\mathrm{C}^{\mathrm{Fe}}=21.8 \cdot \mathrm{C}^{\mathrm{Ptot}}+9954$ \\
\hline & $\mathrm{Fe}_{\text {tot }}-\mathrm{P}_{\text {tot }}$ & summer & 0.8977 & $\mathrm{C}^{\mathrm{Fe}}=36.5 \cdot \mathrm{C}^{\mathrm{Ptot}}+690$ \\
\hline & Fetot-Porg & summer & 0.9978 & $\mathrm{C}^{\mathrm{Fe}}=183 \cdot \mathrm{C}^{\mathrm{Porg}}-5201$ \\
\hline \multicolumn{5}{|l|}{ Dniester River } \\
\hline \multirow{2}{*}{$\begin{array}{l}\text { Sediments } \\
(0-5 \mathrm{~cm})\end{array}$} & $\mathrm{Mn}_{\text {tot }}-\mathrm{P}_{\text {inorg }}$ & summer & 0.9456 & $\mathrm{C}^{\mathrm{Mn}}=2.6 \cdot \mathrm{C}^{\mathrm{Pan} o \mathrm{r}}-25,6$ \\
\hline & Fetot $_{\text {tonorg }}$ & summer & 0.9987 & $\mathrm{C}^{\mathrm{Fe}}=74 \cdot \mathrm{C}^{\mathrm{Panorg}}-6757$ \\
\hline
\end{tabular}

* 0 -P - phosphorus-orthophosphate, $\mathrm{P}_{\text {cond }}-$ condensed phosphorus forms, $\mathrm{P}_{\text {tot }}-$ total phosphorus, $\mathrm{P}_{\text {inorg }}$ - inorganic phosphorus, $\mathrm{P}_{\text {org }}$ - organic phosphorus

In interstitial water of the Prut River sediments, for spring samples, there are positive correlations between dissolved iron and phosphorus-orthophosphate $(r=0.89)$. During of summer, the correlation coefficient between Fediss and condensed phosphorus content was 0.99 , while between Fediss and $0-P$ was 0.88 .

In bottom sediments of the Dniester River, the correlations between iron and manganese content was positive with inorganic phosphorus amount, the correlation coefficients being of 0.94 and 0.99 , respectively (Tab. 3 ).

\section{Conclusions}

The recorded ratio of total iron and phosphorus at sediments surface along the Prut and Dniester Rivers was, in the most cases, greater than 15. This fact indicates that in 
sediments there is enough iron to control the flux of phosphorus from sediments in the water horizon. In interstitial water the Fediss:o-P ratio was greater than 3.6, suggesting that the sediments have a high affinity to phosphates, immobilized its.

In bottom sediments of the Prut and Dniester Rivers the manganese and iron content has correlated positively with the phosphorus forms amount.

\section{References}

1. Methods of Phosphorus Analysis for Soils, Sediments, Residuals, and Waters (2009), Kovar J., Pierzynski G. (eds). 2nd Edition, Southern Cooperative Series Bulletin, vol. 408, 122 p.

2. Matuszewska K., Białkowska I., Bolałek J. (2003) Interdependence between phosphorus forms in sediments and iron in interstitial waters in the Gulf of Gdańsk. International Journal of Oceanography and Hydrobiology, XXXII(1), pp. 5-14.

3. Maassen S., UhImann D., Roske I. (2005) Sediment and pore water composition as a basis for the trophic evaluation of standing waters. Hydrobiologia, 543, pp. 55-70.

4. Lehtoranta J., Heikki P. (2003) Binding of phosphate in sediment accumulation areas of the eastern Gulf of Finland, Baltic Sea. Hydrobiologia, 492, pp. 55-67.

5. Jensen H., Kristensen P., Jeppesen E., Skytthe A. (1992) Iron:phosphorus ratio in surface sediment as an indicator of phosphate release from aerobic sediments in shallow lakes. Hydrobiologia, 235/236, pp. 731-743.

6. Ozkan E., Buyukisik B. (2012) Examination of reactive phosphate fluxes in an eutrophicated coastal area. Environmental Monitoring and Assessment, 184(6), pp. 3443-3454.

7. Jalali M., Peikam E. (2013) Phosphorus sorption-desorption behaviour of river bed sediments in the Abshineh river, Hamedan, Iran, related to their composition. Environmental Monitoring and Assessment, 185(1), pp. 537-542.

8. Techniques of water-resources investigations of the United States Geological Survey (1989), Fishman M., Friedman L. (eds), Book 5, 3d edition, Washington, , 545 p.

9. Examination of Water for Pollution Control, A Reference Handbook (1982) Suess M. (ed), Oxford-New York-Toronto-Sydney-Paris-Frankfurt: World Health Organization, Regional Office for Europe, 1st Edition, Pergamon Press, vol. 2, , 555 p.

10. Jahnke R., Alexandea C., Kostka J. (2003) Advective pore water input of nutrients to the Satilla River Estuary, Georgia, USA. Estuarine, Coastal and Shelf Science, 56, pp. 641-653. 11. Andrieux-Loyer F., Philippon X., Bally G., Kerouel R., Youenou A., Le Grand G. (2008) Phosphorus dynamics and bioavailability in sediments of the Penze' Estuary (NW France): in relation to annual P-fluxes and occurrences of Alexandrium Minutum. Biogeochemistry, 88, pp. 213-231.

12. Wang Q., Li Y. (2010) Phosphorus adsorption and desorption behavior on sediments of different origins. Journal of Soils and Sediments, 10, pp. 1159-1173. 